\title{
POLítica PÚBLICA dE EDUCAÇÃO ESPECIAL NA PERSPECTIVA dA EDUCAÇÃO INCLUSIVA: ESTUDO DE CASO NO MUNICÍPIO DE ARACOIABA- CE
}

\author{
POLICY OF SPECIAL EDUCATION IN THE PERSPECTIVE OF INCLUSIVE EDUCATION: CASE \\ STUDY IN THE MUNICIPALITY OF ARACOIABA-CE
}

\section{POLÍTICA PÚBLICA DE EDUCACIÓN ESPECIAL EN LA PERSPECTIVA DE LA EDUCACIÓN INCLUSIVA: ESTUDIO DE CASO EN EL MUNICIPIO DE ARACOIABA-CE}

Elcimar Simao Martins. E-mail: elcimar@unilab.edu.br Elisangela André da Silva Costa. E-mail: elisangelaandre@unilab.edu.br Sinara Mota Neves de Almeida. E-mail: sinaramota@unilab.edu.br Francisco Vinícius Sampaio da Silva. E-mail: franciscovinicius1@hotmail.com Universidade da Integração Internacional da Lusofonia Afro-Brasileira - UNILAB

\section{RESUMO}

A política nacional de educação especial na perspectiva da educação inclusiva busca desenvolver, de forma satisfatória, as medidas necessárias para a construção de um sistema educacional inclusivo, possibilitando o acesso de pessoas com deficiência aos sistemas de ensino por meio do Atendimento Educacional Especializado (AEE). Pensando assim, o objetivo deste trabalho é analisar, a partir da legislação educacional e do olhar dos sujeitos das práticas educativas, os limites e possibilidades da educação especial na perspectiva inclusiva, no contexto das escolas Pedro Guedes Alcoforado e Nágila Maria Pontes Paz Passos, em Aracoiaba-CE. Realizouse uma pesquisa de abordagem qualitativa do tipo exploratório-descritiva, por meio de técnicas de observação, entrevista, com análise do conteúdo e método interpretacional das narrações dos servidores, pretendendo compreender como ocorrem os processos de gestão educacional na perspectiva da educação especial nas escolas citadas. Foi constatado que a implementação do AEE atende às condições mínimas das normativas legais e que o papel dos servidores influencia positivamente na receptividade da educação especial como forma de inclusão

PALAVRAS-CHAVE: Educação Inclusiva - Brasil. Atendimento Educacional Especializado. Aracoiaba

\begin{abstract}
The national special education policy in the perspective of inclusive education seeks to satisfactorily implement the necessary measures for the construction of an inclusive educational system, enabling the access of people with disabilities to education systems through the Specialized Educational Assistance (AEE). The aim of this paper is to describe, from the educational legislation and the perspective of the subjects of the educational practices, the limits and possibilities of the special education in the inclusive perspective, in the context of the schools Pedro Guedes Alcoforado and Nágila Maria Pontes Paz Passos in Aracoiaba -Ce. Therefore, a qualitative research of the exploratory-descriptive type was carried out, through techniques of observation, interview, with analysis of the content and interpretative method of narrations of the servers, pretending to understand how the processes of educational management occur in the perspective of the special education in the mentioned schools. It was verified that the implementation of the ESA meets the minimum conditions of the legal regulations and that the role of the servants positively influences the receptivity of special education as a form of inclusion
\end{abstract}

KEYWORDS: Inclusive Education - Brazil. Specialized Educational Assistance, Aracoiaba. 
La política nacional de educación especial en la perspectiva de la educación inclusiva busca aplicar de forma satisfactoria las medidas necesarias para la construcción de un sistema educativo inclusivo, posibilitando el acceso de personas con discapacidad a los sistemas de enseñanza a través de la Atención Educativa Especializada (AEE). El objetivo de este trabajo es describir, a partir de la legislación educativa y de la mirada de los sujetos de las prácticas educativas, los límites y posibilidades de la educación especial en las perspectivas inclusivas, en el contexto de las escuelas Pedro Guedes Alcoforado y Nágila Maria Pontes Paz Pasos en Aracoiaba -c. Por lo tanto, se realizó una investigación de abordaje cualitativo del tipo exploratoriodescriptivo, por medio de técnicas de observación, entrevista, con análisis del contenido y método interpretacional de narraciones de los servidores, pretendiendo comprender cómo ocurren los procesos de gestión educativa en la perspectiva de la gestión educación especial en las escuelas citadas. Se constató que la implementación del AEE atiende a las condiciones mínimas de las normativas legales y que el papel de los servidores influye positivamente en la receptividad de la educación especial como forma de inclusión

PALABRAS-CLAVE: Educación Inclusiva - Brasil. Atención al cliente. Aracoiaba

\section{INTRODUÇÃO}

A partir das últimas décadas do século XX, o movimento mundial pela educação inclusiva tem ganhado destaque nas discussões de organismos internacionais que norteiam, em certo sentido, a atuação do Estado, tendo em vista uma maior participação deste no combate ao crescimento da desigualdade social por meio da criação e implantação de Políticas Públicas que fazem frente às necessidades oriundas da coletividade sob sua responsabilidade.

A educação inclusiva representa um modelo educacional alicerçado na concepção dos direitos humanos, que busca harmonizar os conceitos de igualdade e diferença como valores inseparáveis e que vem progredindo em relação à ideia de justiça social ao contextualizar as circunstâncias históricas da produção de fatores de exclusão tanto na escola quanto fora dela.

Ao admitir que os problemas enfrentados nos sistemas de ensino demonstram certo grau de ineficiência e ineficácia nas ações adotadas pelo governo no combate a exclusão social, evidencia-se a necessidade de enfrentar as práticas discriminatórias e a criação de meios para solucioná-las. Neste sentido, a Educação Inclusiva contrai função de destaque nas discussões acerca do papel da escola como mecanismo primordial para redução dos índices e da lógica da exclusão.

Entende-se por Escola Inclusiva, aquela capaz de atender a todos os alunos, cada um com sua especificidade; essa exigência perpassa modificações na atuação da escola não somente no campo pedagógico, mas também estrutural e culturalmente. Por meio das políticas educacionais, devem ser extintos os obstáculos à educação dos alunos com deficiências, garantindo assistência às necessidades educacionais especiais, e com isso 
incentivar a cooperação entre os stakeholders ${ }^{1}$. Dentro desse contexto, podemos inferir que a educação inclusiva coaduna um novo nexo pedagógico direcionado para as diversas maneiras de aprendizado de crianças e jovens e para enaltecer a diversidade nos variados espaços e modos de relacionar-se.

Dentro das instituições escolares responsáveis pela prestação dos serviços de Atendimento Educacional Especializado (AEE) as escolas públicas adquirem papel de destaque na oferta desse tipo de serviço. Desse modo, os locais escolhidos como objetos de investigação foram as seguintes instituições de ensino: Escola Coronel Pedro Guedes Alcoforado e Escola de Ensino Fundamental Dra. Nágila Maria Pontes Paz Passos, ambas pertencentes ao município de Aracoiaba, no Maciço de Baturité, Ceará.

Assim, diante da importância da educação como um dos pilares para o pleno desenvolvimento do ser humano pode-se dizer que o problema foco dessa pesquisa, concentra-se em questionar: em que medida as políticas de inclusão social na perspectiva da educação inclusiva estão sendo desenvolvidas no município de Aracoiaba de forma a proporcionar o acesso a uma educação de qualidade a todos os estudantes com deficiência matriculados nas escolas Coronel Pedro Guedes Alcoforado e Dra. Nágila Maria Pontes Paz Passos?

\section{REFERENCIAL TEÓRICO}

Quando se discute a garantia de direitos da pessoa com deficiência na contemporaneidade brasileira, o marco inicial deve ser a Constituição Federal de 1988, que em sentido holístico, é o documento que assegura a cada um em particular e a todos o usufruto de seus direitos. A CF/88 proporciona o direito à educação a todos os cidadãos de duas formas distintas:

De forma genérica: considerando a pessoa com deficiência simplesmente como "pessoa" e, assim, em igualdade de condições com as pessoas que não têm deficiência, e de forma especifica, expressamente fazendo referência à "pessoa com deficiência". De forma genérica, as pessoas com deficiência, pelo simples fato de serem pessoas, dispõem do direito à igualdade, saúde, educação, cultura, esporte, acesso à justiça e defesa pelo Ministério Público, entre outros. De forma específica, as pessoas com deficiência dispõem do direito ao trabalho, previdência e assistência social, educação e acessibilidade. (ARRUDA, 2010, p. 09).

\footnotetext{
${ }^{1}$ Segundo Secchi (2010, p. 125) são "todos os portadores de interesses nas atividades de uma organização (uso nas ciências da administração), ou nos impactos de uma política pública (uso na área das políticas públicas)". 
No âmbito jurídico, de fato, uma das grandes preocupações é com a aplicabilidade de forma eficiente e eficaz do princípio da Igualdade, visando a garantir de forma exequível outro pilar fundamental da democracia: o princípio da Justiça.

A doutrina e a jurisprudência, embora ofertem mecanismos que busquem solucionar, ou ao menos, diminuir o máximo possível as situações de discriminação por meio de leis, decretos e portarias que, admitam em certos casos, a aplicação de tratamento diferenciado para indivíduos portadores de algum tipo de deficiência, ainda não foram suficientes para erradicar as situações de exclusão.

Mesmo com tantas garantias constitucionais, corriqueiramente, encontram-se situações em que os critérios para a aplicação do direito à igualdade baseiam-se somente no juízo crítico da razoabilidade e não no do tratamento diferenciado. Com isso, para saber se determinada ação diferenciada é válida ou não é necessário utilizar um dos seguintes critérios:

a) Necessidade de identificação do fator adotado como motivo de diferenciação;

b) Não admissão de tratamentos desiguais, com base direta ou indireta, em atributos subjetivos do ser humano (raça, sexo, religião, crença, deficiência, língua, opinião política, origem nacional, filiação, ente outros), que tenham por objetivo ou resultado a anulação, o impedimento, o prejuízo, ou a restrição do reconhecimento, gozo ou exercício de direitos humanos e liberdade fundamentais;

c) Admissão de exceções a essa regra, desde que possam ser identificadas objetivamente, pois dizem respeito apenas à interdição, em caso de pessoas com deficiência e a proteção do direito à vida, cabendo, ainda, nesse último caso, a análise da razão da medida;

d) Possibilidade de adoção de medidas especiais (discriminação positiva), desde que não sejam relacionadas à religião ou crença e que visem à facilitação do gozo ou exercício do direito, e não a sua negação;

e) Necessidade de que tais medidas razoáveis, ou proporcionais, que não impliquem manutenção de direitos separados; que a pessoa interessada, ou seu responsável não esteja obrigada a aceitar tal tratamento diferenciado ou mesmo a preferência; e que eventuais medidas afirmativas sejam temporárias. (FÁVERO; PANTOJA; MONTOAN, 2007, p. 15)

Para compreender melhor esse tratamento diferenciado é preciso atentar para algumas questões fundamentais, a saber: No contexto atual, qual a definição de AEE? Qual é o fator de diferenciação utilizado para indicar o usufruto desse serviço? Quem é seu público-alvo e como se caracteriza? 
Em primeiro lugar, no decreto número 6.571, de 17 de Setembro de 2008, em seu art. $1^{\circ}, \S 1^{\circ}$ define AEE como um "conjunto de atividades, recursos de acessibilidade e pedagógicos organizados institucionalmente, prestado de forma complementar ou suplementar à formação dos alunos no ensino regular" (BRASIL, 2010a, p. 28).

Em segundo lugar, o fator de diferenciação utilizado para que se possa usufruir desse serviço diferenciado é a deficiência. Ora, deficiência é um atributo subjetivo do ser humano, portanto, é proibido o uso de critério de diferenciação, e consequentemente a segregação de alunos com deficiência para salas especiais.

Em terceiro lugar, no decreto 7.611 , de 17 de Novembro de 2011 , no art. $1^{\circ}, \S 1^{\circ} \mathrm{diz}$ que "para fins deste decreto, considera-se público-alvo da educação especial as pessoas com deficiência, com transtornos globais do desenvolvimento e com altas habilidades ou superdotação". Dessa forma, vemos que o direito à educação possui suas particularidades, ou seja, não é qualquer tipo de acesso à educação que atende as exigências do princípio da igualdade de acesso e permanência na escola versado no artigo 208, inciso primeiro da $\mathrm{CF} / 88$.

\footnotetext{
A União prestará apoio técnico e financeiro aos sistemas públicos de ensino dos Estados, do Distrito Federal e dos Municípios, na forma deste Decreto, com a finalidade de ampliar a oferta do atendimento educacional especializado aos alunos com deficiência, transtornos globais do desenvolvimento e altas habilidades ou superdotação, matriculados na rede pública de ensino regular. (BRASIL, 2010a, p. 28).
}

Os alunos do AEE, por possuírem limitações que os demais alunos não têm, utilizam instrumentos e métodos de aprendizagem que os demais alunos não precisam. Por isso, é preciso ainda que o AEE em sua execução, não seja um fato gerador de constrangimento àqueles que são seus beneficiados (alunos e família).

\subsection{Aspectos Legais e Pedagógicos do AEE}

A Educação Especial é definida pela resolução CNE/CEB no 4/2010 (art. 29) como uma "modalidade de ensino transversal em todos os níveis, etapas e modalidades de ensino, é parte integrante da educação regular, devendo ser prevista no projeto político-pedagógico da unidade escolar" (BRASIL, 2010d, p. 10).

O Conselho Nacional de Educação no artigo $5^{\circ}$ da resolução $n^{\circ} 4 / 2009$, que estabelece as diretrizes operacionais do AEE na educação básica, legisla que: 
O AEE é realizado, prioritariamente, na sala de recursos multifuncionais da própria escola ou em outra escola de ensino regular, no turno inverso da escolarização, não sendo substitutivo às classes comuns, podendo ser realizado, também, em centro de Atendimento Educacional Especializado da rede pública ou de instituições comunitárias, confessionais ou filantrópicas sem fins lucrativos, conveniadas com a Secretaria de Educação ou órgão equivalente dos Estados, Distrito Federal ou dos Municípios. (BRASIL, 2009, p. 02)

Com isso, vemos que o entendimento acerca da educação inclusiva, vai além de uma simples inserção do aluno em sala de aula, mas compreende a totalidade do itinerário educacional, albergando assim, uma mudança de cultura educacional e um processo de transformação estrutural da escola para atender as demandas do público do AEE. A escola deve colocar em prática sua função social, elaborando uma proposta de atuação pedagógica que valorize as diferenças e a diversidade. Esse pensamento é reforçado pela resolução $\mathrm{CNE} / \mathrm{CEB} \mathrm{n}^{\circ} 4 / 2010$ no $\left(\operatorname{art} .29, \S 1^{\circ}\right)$ ao afirmar que:

Os sistemas de ensino devem matricular os estudantes com deficiência, transtornos globais do desenvolvimento e altas habilidades/superdotação nas classes comuns do ensino regular e no Atendimento Educacional Especializado (AEE), complementar ou suplementar à escolarização, ofertado em salas de recursos multifuncionais ou em centros de AEE da rede pública ou de instituições comunitárias, confessionais ou filantrópicas sem fins lucrativos. (BRASIL, 2010d, p. 10).

Por conseguinte, todos os alunos da educação especial devem ser matriculados em salas comuns e ter acesso ao serviço do AEE no contra turno ao ensino regular, com espaço adequado e com recursos suficientes para o cumprimento adequado dos seus objetivos. A resolução CNE/CEB n ${ }^{\text {4 }}$ /2009 (art.04, incisos I, II e III) define o público alvo do AEE como:

I - Alunos com deficiência: aqueles que têm impedimentos de longo prazo de natureza física, intelectual, mental ou sensorial; II - Alunos com transtornos globais do desenvolvimento: aqueles que apresentam um quadro de alterações no desenvolvimento neuropsicomotor, comprometimento nas relações sociais, na comunicação ou estereotipias motoras. Incluem-se nessa definição alunos com autismo clássico, síndrome de Asperger, síndrome de Rett, transtorno desintegrativo da infância (psicoses) e transtornos invasivos sem outra especificação; III - Alunos com altas habilidades/superdotação: aqueles que apresentam um potencial elevado e grande envolvimento com as áreas do conhecimento humano, isoladas ou combinadas: intelectual, liderança, psicomotora, artes e criatividade. (BRASIL, 2009, p. 01) 
A resolução CNE/CEB n ${ }^{\circ}$ 4/2009 no (art.10) ainda destaca que "o projeto pedagógico da escola de ensino regular deve institucionalizar a oferta do AEE". Todavia essa institucionalização do AEE prevê uma série de exigências para sua implementação, as quais estão dispostas nos incisos I ao VII no (art. 10) da supracitada resolução, quais sejam:

I - Sala de recursos multifuncionais: espaço físico, mobiliário, materiais didáticos, recursos pedagógicos e de acessibilidade e equipamentos específicos; II - matrícula no AEE de alunos matriculados no ensino regular da própria escola ou de outra escola; III - cronograma de atendimento aos alunos; IV - plano do AEE: identificação das necessidades educacionais específicas dos alunos, definição dos recursos necessários e das atividades a serem desenvolvidas; $\mathrm{V}$ - professores para o exercício da docência do AEE; VI - outros profissionais da educação: tradutor e intérprete de Língua Brasileira de Sinais, guia-intérprete e outros que atuem no apoio, principalmente às atividades de alimentação, higiene e locomoção; VII redes de apoio no âmbito da atuação profissional, da formação, do desenvolvimento da pesquisa, do acesso a recursos, serviços e equipamentos, entre outros que maximizem o AEE. (BRASIL, 2009, p. 02)

Outro fator importante para que essa política de inclusão tenha êxito é, sem dúvida, o professor, pois, é ele, de fato, o principal responsável pela operacionalização das estratégias utilizadas para combater a segregação de estudantes com deficiência. A resolução CNE/CEB $n^{0} 4 / 2009$ no (art.12) ao tratar sobre a atuação do professor no AEE diz que ele "deve ter formação inicial que o habilite para o exercício da docência e formação específica para a Educação Especial”. No art.13 (incisos I -VIII) descreve quais as atribuições do seu cargo:

I - identificar, elaborar, produzir e organizar serviços, recursos pedagógicos, de acessibilidade e estratégias considerando as necessidades específicas dos alunos público-alvo da Educação Especial; II - elaborar e executar plano de Atendimento Educacional Especializado, avaliando a funcionalidade e a aplicabilidade dos recursos pedagógicos e de acessibilidade; III - organizar o tipo e o número de atendimentos aos alunos na sala de recursos multifuncionais; IV - acompanhar a funcionalidade e a aplicabilidade dos recursos pedagógicos e de acessibilidade na sala de aula comum do ensino regular, bem como em outros ambientes da escola; V - estabelecer parcerias com as áreas intersetoriais na elaboração de estratégias e na disponibilização de recursos de acessibilidade; VI - orientar professores e famílias sobre os recursos pedagógicos e de acessibilidade utilizados pelo aluno; VII - ensinar e usar a tecnologia assistiva de forma a ampliar habilidades funcionais dos alunos, promovendo autonomia e participação; VIII - estabelecer articulação com os professores da sala de aula comum, visando à disponibilização dos serviços, dos recursos pedagógicos e de acessibilidade e das estratégias que promovem a participação dos alunos nas atividades escolares. (BRASIL, 2009, p. 03) 


\section{MATERIAIS E MÉTODOS}

A presente pesquisa é uma investigação de abordagem qualitativa, que segundo Souza et.al (2013, p. 15) "usa a subjetividade que não pode ser traduzida em números. É mais descritiva", ou seja, não objetivando quantificar ações ou a repetição de padrões, mas compreender os fenômenos sociais que envolvem a execução das políticas de Educação Especial na perspectiva da educação inclusiva de alunos com deficiência no ensino regular das duas escolas municipais de Aracoiaba, além de sua efetividade, a partir da visão de diferentes atores sociais envolvidos no processo, a saber, os professores e os gestores escolares.

Para que fosse possível delinear o procedimento técnico mais adequado para a coleta de dados, a classificação da pesquisa com relação aos seus objetivos como descritiva, exploratória e explicativa é importante, como afirma Gil (2002, p. 43) para "o estabelecimento de seu marco teórico, ou seja, para possibilitar uma aproximação conceitual". Sendo assim, foi realizado um estudo de campo, associado à pesquisa bibliográfica e documental.

Dessa forma, para a coleta de dados foram realizadas entrevistas semiestruturadas, que segundo Piana (2009, p. 179), trata-se de "um procedimento formal de se obter informações por meio da fala dos atores sociais". Dessa forma, foi realizada uma triagem dos tópicos mais relevantes da problemática de pesquisa a serem abordados, em um roteiro previamente definido. Concomitantemente à entrevista utilizou-se ainda a técnica de observação, que segundo Godoy $(1995$, p. 27) em trabalhos de abordagem qualitativa "frequentemente é combinada com a entrevista.". Em posse desses dados, foi possível realizar a interpretação dos dados coletados.

As entrevistas foram realizadas com os agentes integrados à gestão das políticas educacionais na perspectiva da educação inclusiva que envolve: a) Coordenadora Pedagógica da escola Dra. Nágila; b) Professores do AEE das duas instituições de ensino.

As informações adquiridas com as entrevistas foram reunidas e estruturadas por meio da técnica de análise de conteúdo que, segundo Mozzato e Grzybovski (2011, p. 734), é “um conjunto técnicas de análise das comunicações, que utiliza procedimentos sistemáticos e objetivos de descrição dos conteúdos das mensagens". 


\section{ANÁLISE DOS DADOS E RESULTADOS}

\subsection{Descrição do cenário da pesquisa}

A Escola de Ensino Fundamental Dra. Nágila Maria Pontes Paz Passos atua no âmbito dos anos finais do Ensino Fundamental ( $6^{\circ}$ ao $9^{\circ}$ ano) e da Educação de Jovens e Adultos (EJA). Já a Escola Coronel Pedro Guedes Alcoforado atua com os anos iniciais do Ensino Fundamental ( $1^{\circ}$ ao $5^{\circ}$ ano). A Escola. Dra. Nágila atualmente possui um quantitativo de 735 alunos regularmente matriculados e dispõe de uma Sala de Recursos Multifuncionais (SRM), em que 17 alunos, que compõem o perfil exigido para o público alvo do serviço de Educação Especial utilizam o serviço de AEE ofertado na infraestrutura da instituição.

A escola Coronel Pedro Guedes por sua vez, possui um quantitativo de 449 alunos regularmente matriculados e, em suas instalações, possui duas SRMs, onde são atendidos um total de 31 alunos, em duas turmas distintas, com 18 e 13 alunos respectivamente.

Nessa investigação denominaremos por Coordenador Pedagógico, o profissional que trabalha na escola Dra. Nágila e professor $X$, aquele que desenvolve o serviço de AEE na supracitada escola. Chamaremos de professores $\mathrm{Y}$ e Z, os profissionais que atuam nas duas SRM da escola Pedro Guedes, nas salas com 18 e 13 alunos respectivamente. Vale salientar que, do percentual de alunos regularmente matriculados na escola Pedro Guedes, apenas 7\% correspondem ao público alvo do AEE.

As duas instituições juntas atendem a um total de 1184 alunos regularmente matriculados e 48 é o somatório do total do número de alunos que participam do AEE nas duas instituições. Esse número representa apenas o quantitativo de alunos que dispunham de laudo médico já arquivado na secretaria das respectivas instituições pelos professores $\mathrm{X}, \mathrm{Y}$ e $\mathrm{Z}$ no momento que a pesquisa foi realizada. É importante destacar que o laudo médico é um requisito necessário para que o aluno esteja habilitado para participar do serviço de AEE, pois este define se o mesmo compõe o perfil expresso na resolução CNE/CEB no 4/2009 (art.4, incisos 1 - III), ou se apenas possui dificuldade de aprendizado por fatores que não são oriundos de algum tipo de deficiência.

Ao elaborar a Lei Orçamentária Anual (LOA), o município precisa prever todos os gastos e as despesas que serão realizados no exercício financeiro seguinte para poder dispor dos recursos financeiros de forma correta, tanto os provenientes por meio dos repasses da união, quanto aqueles gerados pelo próprio município, motivado de sua economia local. 
A resolução CNE/CEB n 4/2009 no seu art.8, parágrafo único, na alínea a, dispõe que:

Serão contabilizados duplamente, no âmbito do FUNDEB, de acordo com o Decreto $\mathrm{n}^{\mathrm{o}} 6.571 / 2008$, os alunos matriculados em classe comum de ensino regular público que tiverem matrícula concomitante no AEE. Parágrafo único. O financiamento da matrícula no AEE é condicionado à matrícula no ensino regular da rede pública, conforme registro no Censo Escolar/MEC/INEP do ano anterior, sendo contemplada: a) matrícula em classe comum e em sala de recursos multifuncionais da mesma escola pública.

A informação do quantitativo de alunos deve ser fiel, pois a cada ano o MEC e o Ministério da Fazenda divulgam um valor mínimo anual investido por aluno da educação básica. Tal valor é alterado anualmente, pois é estipulado tendo como base de cálculo a estimativa de contribuições e arrecadação de impostos.

A Portaria Interministerial $n^{\circ} 8 / 2016$ definiu que em 2017, o valor investido por aluno foi de $\mathrm{R} \$ 2.875,03$. Essa portaria difere da anterior, a Portaria Interministerial $n^{\circ} 7 / 2016$, pois traz como novidade que os repasses serão feitos em parcelas mensais de Janeiro de 2017 a Janeiro de 2018, sendo repassado em conjunto a "complementação da União" e a "complementação do piso".

No momento da visita às duas instituições as deficiências encontradas no ato da pesquisa foram: Autismo (08 alunos), Surdez (03 alunos), Deficiência Intelectual (DI - 28 alunos), Hidrocefalia (04 alunos), Síndrome de Down (02 alunos) e Paralisia Cerebral (PC 01 aluno).

\subsection{Análise da aplicabilidade da política educacional na perspectiva da educação inclusiva: ideal normativo versus realidade encontrada}

Ao analisarmos o papel da escola, o primeiro documento norteador de medidas e ações a serem executadas durante o ano letivo é o Projeto Político-Pedagógico (PPP), posto que

O projeto político-pedagógico de uma escola é o instrumento teórico metodológico, definidor das relações da escola com a comunidade a quem vai atender, explicita o que se vai fazer, porque se vai fazer, para que se vai fazer, para quem se vai fazer e como se vai fazer. É nele que se estabelece a ponte entre a política educacional do município e a população, por meio da definição dos princípios, dos objetivos educacionais, do método de ação e das práticas que serão adotadas para favorecer o processo de desenvolvimento e de aprendizagem das crianças e adolescentes da 
comunidade. Seu desenvolvimento requer reflexão, organização de ações e a participação de todos - professores, funcionários, pais e alunos, num processo coletivo de construção. Sua sistematização nunca é definitiva, o que exige um planejamento participativo, que se aperfeiçoa constantemente durante a caminhada. (BRASIL, 2004d, p. 09).

Das duas instituições pesquisadas, somente a escola Dra. Nágila já havia elaborado o PPP do ano de 2017. No momento da pesquisa, a escola Pedro Guedes ainda estava em processo de elaboração e aprovação do PPP. Fato este que prejudica a atuação da escola na prestação do serviço de AEE, pois "nenhuma escola poderá alcançar objetivos significativos, para os alunos e para a comunidade na qual se encontra inserida, se não tiver um projeto que norteie e dê suporte para a ação de cada um de seus agentes" (BRASIL, 2004d, p. 10).

Nesse processo é de fundamental importância a atuação da gestão escolar, ou seja, a direção. Dentro do escopo dos responsáveis pela direção da organização, a Coordenação Pedagógica tem papel de destaque, pois sua função passa por buscar fazer parcerias com os diferentes atores sociais envolvidos no processo educacional (instituições públicas, privadas, empresas e organizações comunitárias).

Seu trabalho não pode ser executado em gabinete, mas sim, na realidade do cotidiano das salas de aula. Ela precisa ser ativa e presente em todas as instâncias da escola. É ela que vai promover a unidade da equipe na busca do sucesso didático-pedagógico da escola, fazendo a mediação entre as diversas áreas do conhecimento e entre os diferentes profissionais. (BRASIL 2004d, p. 13-14).

Sabendo da importância do papel e atuação eficiente, eficaz e efetiva, do coordenador pedagógico, a escola Dra. Nágila ao elaborar seu regimento escolar para o ano de 2017 em seu (art. 11 incisos $\mathrm{i}$ - x) enumera as atribuições da atuação do coordenador pedagógico que servem de parâmetro para execução de seu trabalho, bem como de critérios para saber se sua função está sendo bem desempenhada:

Organizar os serviços pedagógicos da instituição, assegurando qualidade e eficiência do processo ensino-aprendizagem; Assinar os documentos relativos à escrituração escolar, juntamente com o secretário escolar; Propor medidas e baixar diretrizes, normas e instruções a respeito do regime, didático e disciplinar; Coordenar a elaboração e execução do projeto pedagógico da Instituição; Promover a integração escola, comunidade e família; Representar a Instituição onde se fizer necessário; Convocar e presidir as sessões da Congregação de Professores; Constituir comissões de professores e especialistas para decidir assuntos de ordem pedagógica e disciplinar; Cumprir e fazer cumprir o Regimento Escolar e a legislação 
educacional vigente; Dar conhecimento a toda comunidade escolar sobre o presente Regimento (ARACOIABA, 2017a, p. 06-07).

De acordo com o regimento escolar da escola Dra. Nágila, no (art. 11 inciso IV) é uma das competências do coordenador pedagógico "coordenar a elaboração e execução do projeto pedagógico da Instituição". Dessa forma, no que tange a gestão administrativa das duas instituições, essa está melhor estruturada do que a escola Pedro Guedes, que não dispunha do PPP para no ano de 2017 finalizado.

O PPP é o documento norteador das ações escolares para o ano letivo e, se este não for bem elaborado, a escola não poderá realizar as melhores ações possíveis para o cumprimento de suas obrigações. Dessa forma, o serviço do AEE fica prejudicado, a mercê de improvisos, tanto da gestão escolar quanto dos próprios professores.

De acordo com o PPP de 2017 da escola Dra. Nágila, na seção que orienta e regulamenta a proposta de atendimento dos alunos público alvo da educação especial, esta legisla que "orienta sua ação nos fins da Educação Nacional, previstos no Art. $2^{\circ}$ e artigo $3^{\circ}$, Inciso I da Lei Federal - LDB - 9394/96 e no Documento das Diretrizes Básicas da Educação Especial do Estado do Ceara”. Com isso,

Para atender às especificidades dos alunos públicos - alvo da educação especial, no processo educacional e, no âmbito de uma atuação mais ampla, a escola orienta-se sua organização curricular no desenvolvimento de todos os alunos e no desenvolvimento de práticas colaborativas na escola regular.

A escola atende ao Parecer CNE/CEB N $\mathrm{N}^{\circ} 17 / 01$, que define que o projeto pedagógico de uma escola inclusiva deverá atender ao princípio da flexibilidade para que o acesso ao currículo seja adequado às condições do aluno, favorecendo seu processo escolar. (ARACOIABA, 2017 b, p. 05)

Pelo fato da escola Pedro Guedes não possuir um PPP finalizado, suas ações tanto no campo da gestão administrativa escolar quanto na gestão pedagógica, ficam bastante limitadas no que se refere à avaliação da atuação dos próprios funcionários da instituição no tocante a exequibilidade de suas funções e da avalição dos próprios alunos que compõem o público alvo do AEE.

Outra variável bastante importante, nos processos de eficiência e eficácia de tais medidas é a atuação da família, principalmente com relação ao apoio dado à escola e aos alunos com deficiência. Assim, 
Faz-se necessário que a família construa conhecimentos sobre as necessidades especiais de seus filhos, bem como desenvolva competências de gerenciamento do conjunto dessas necessidades e potencialidades. É importante que os profissionais desenvolvam relações interpessoais saudáveis e respeitosas, garantindo-se assim maior eficiência no alcance de seus objetivos. (BRASIL, 2004c, p. 07)

A relação com a família foi um dos principais problemas enunciados pelos professores $\mathrm{X}, \mathrm{Y}$ e $\mathrm{Z}$ nas entrevistas, recebendo também destaque as respostas do Coordenador Pedagógico A.

Uma das principais barreiras é a família, porque ela em si não dá apoio. Porque se nós tivéssemos mais o apoio da família, a integração seria muito melhor. Uma das maiores dificuldades que nós temos é a própria família. A família pelo medo, eles tem medo de eles serem magoados e acabam protegendo demais, se tornam superprotetores e estão prejudicando os filhos, eles não estão conseguindo evoluir devido a isso. (Coordenador Pedagógico A)

É difícil por que as vezes eles [a família] simplesmente não aceitam. Não aceitam e ponto final. E ac criança sair prejudicada, porque até tem o Atendimento aqui na escola mas em casa, não recebe acolhimento da forma deveria receber. É dificil! É realmente bem complicado. (Professor X)

Tem país de vários tipos uns protegem demais e outros não dão a devida importância. Mas tem alguns que são muito presente, como a mãe da (aluno $B$ - omitimos o nome da aluno) que compra livro, pesquisa, pergunta, enfim, acompanha muito de perto, ele realmente deseja a melhoria de vida da sua filha. (Professor Y)

O pior é quando você lida com a família que não aceita que a criança tem, porque precisa-se trabalhar primeiro com a aceitação da família, de uma jeito muito delicado porque você não chegar e dizer pra mãe. (Professor Z)

Dentro dessa perspectiva de mudança cultural que a família necessita passar, o município tem um papel de fundamental importância para a construção desse novo panorama, pois é o responsável pela implementação, controle, avaliação e correção das ações que precisam ser ajustadas para atingir seus objetivos.

Para tanto, faz-se necessário que o município tenha um Plano Municipal de Educação (PME) bem estruturado, que conheça a realidade e que conceba as estratégias planejadas de atuação com base nas especificidades da região onde se localiza, de acordo com as necessidades e características da população;

No município de Aracoiaba, o PME é regulado pela Lei $n^{\circ} 1.162 / 2015$, aprovada em 06 de Maio de 2015. Vale ressaltar que, embora tenha pouco mais de dois anos de sua 
aprovação o PME atualmente está em processo de revisão. Com relação ao AEE, a sua regulação e implementação estratégica de ações planejadas pelo município se dá por meio do Projeto Educação Inclusiva, de Fevereiro de 2015.

Portanto, o trabalho nas salas de recursos multifuncionais - SEM é de fato um importante mecanismo de mudanças no contexto educacional e no atendimento educacional especializado. Neste tocante, com a eficiência desse atendimento, inicia-se o processo de modificação da cultura que segregava estes sujeitos e passa a incorporar nos ambientes educacionais uma postura mais humana sobre o sentido de inclusão. (ARACOIABA, 2015, p. 04)

É importante destacar que, embora o projeto seja executado desde 2015, este não foi aprovado na Câmara dos Vereadores de Aracoiaba, o que dá características de ilegalidade à sua execução, embora todos os seus atos sejam legitimados pela população beneficiária.

Devido a esse caráter de ilegalidade, algumas medidas que deveriam ser desenvolvidas pelo município para que a política fosse melhor implementada, tornam-se enviesadas e desarranjadas, pois se o Projeto Educação Inclusiva ainda não foi aprovado, significa que o PME do município não está alinhado com o Plano Nacional de Educação (PNE) e o Programa de Educação Especial (PEE), o que enfraquece suas ações e dificulta sua atuação e aquisição de verba junto ao FUNDEB.

Por causa do desajuste em equilibrar a legalidade dos atos com a legitimidade popular, o AEE, nas duas instituições sofre dificuldades de aplicação e o grau de efetividade do município, ou seja, sua capacidade de gerar os resultados esperados vai se perdendo e, consequentemente, a eficiência do serviço e a eficácia das ações são comprometidas e os resultados esperados não são alcançados por causa da dificuldade em corroborar as ações legítimas da atuação municipal com os atos legais de sua obrigação, enfraquecendo a execução da política de educação especial na perspectiva da educação inclusiva.

Com relação aos materiais disponíveis nas duas SRM da escola Pedro Guedes foi informado pela coordenação escolar que todo o material em sala foi disponibilizado pela própria escola, como um micro computador que foi realocado da sala da direção para uma das SRM e o restante do material utilizado no atendimento, grande parte é produzido pelos professores; esse fato é válido para as duas instituições.

Isso inviabiliza o aumento na prestação do serviço, pois se faltam professores não há possibilidade de expansão da ação. Cada atendimento deve ser feito, de acordo com a 
resolução CNE/CEB no 4/2009 no (art.5) "no turno inverso da escolarização" e com cerca de 50 minutos de duração e duas seções semanais realizadas no turno inverso. Esse problema de gestão dificulta a realização do direito de todos à educação, pois faz com que os professores sejam obrigados a rejeitar esses alunos por não terem mais espaço e condições para a realização de suas funções.

A demanda é muito grande e nós não temos mais como receber. Porque se a gente começar a colocar somente um atendimento por semana, esse atendimento não vão ter o resultado esperado e o mesmo aproveitamento.

Esse é um problema de Gestão de Políticas Públicas mesmo. Falta curso e formação. (Informação verbal extraída de entrevista com os professores $\mathrm{Y}$ e Z das escolas Coronel Pedro Guedes em 04 Ago. 2017)

Mesmo com os obstáculos encontrados na execução da política de educação especial na perspectiva da educação inclusiva no município de Aracoiaba, especificamente, nas escolas Coronel Pedro Guedes e Dra. Nágila, os servidores veem com bons olhos as estratégias utilizadas pela política educacional municipal para promover a inclusão de alunos com deficiência.

\footnotetext{
A importância do AEE, da Sala de Recursos Multifuncionais é pra isso. Eles trabalham diferenciado com cada nível, com cada deficiência. Essa importância e quando traz pra sala de aula a socialização, ele passa a conviver com crianças da idade dela e se ele é um adolescente, ela vai seguindo aquela regra, aquela brincadeira na hora do recreio, convivendo socialmente, quer dizer há uma evolução, ele tem que passar por todas as fases e se ele tem um colega que está naquele nível que ele está convivendo, ouvindo ele falar, a criança vai se integrando e isso é importante para ele. Até pra conviver socialmente ele nunca vai ser igual, ninguém é igual, nós mesmo temos nossas limitações, mas o que eu acho mais importante é essa integração que está havendo. (Informação verbal extraída de entrevista com coordenador pedagógico A em 04 Ago. 2017)
}

O processo de interação entre escola e município é fundamental para que haja de fato a melhoria da qualidade de vida desses alunos, embora várias medidas precisem ser revistas, avaliadas e reimplantadas para que as ações do município e das escolas estejam em consonância com os dispositivos legais do estado e do país que norteiam as ações da educação especial.

De fato, mesmo com pontos a melhorar, o município de Aracoiaba deu um passo na construção de um sistema educacional inclusivo que acolha a todos os alunos independentemente de suas dificuldades de aprendizado. 


\section{CONSIDERAÇÕES FINAIS}

De um modo geral, percebeu-se que a efetivação da educação especial nas escolas do ensino regular minimamente se ajusta às condições enunciadas na legislação, proporcionando assim perspectivas de mudança dos paradigmas educacionais referente à inclusão. Porém, nos dispositivos legais, cuja sua efetivação ainda não é realizada com a excelência que é exigida, é perceptível a vontade de melhoria, por parte dos servidores envolvidos, em especial dos professores, que têm suas ações em parte limitada, em virtude da falta de um cumprimento mais eficiente, eficaz e efetivo dos dispositivos legais por parte do município e de uma melhor administração dos recursos de financiamento na área da educação especial.

Além disso, constatou-se que das duas instituições de ensino a escola Dra Nágila desenvolve um apoio pedagógico às ações do AEE de forma mais organizada, por causa do PPP já elaborado, ao passo que a escola Pedro Guedes, embora ofereça o serviço de AEE, não possui ainda o PPP de 2017 concluído, estando ainda em processo de finalização, contando para a realização do AEE com o planejamento de ações estratégicas dos professores $\mathrm{X}$ e Y, ao passo, que a escola Dra. Nágila consegue articular melhor as ações em virtude das medidas utilizadas na educação especial já estarem inseridas no seu planejamento anual de ação no PPP.

Constatou-se ainda que o papel dos profissionais envolvidos, em especial, dos professores e do coordenador pedagógico, influenciam positivamente a aceitação da educação especial na perspectiva da educação inclusiva. E que uma grande barreira para a execução de forma satisfatória da política educacional do município é a família, por ter ainda muito receio com o tratamento dos outros aos seus filhos com deficiência.

Outra variável que apareceu como entrave para que essa política pública alcance os resultados desejados foi a relação da família com a escola. Constatou-se que as duas escolas buscam manter um diálogo constante com as famílias para esclarecer acerca das dificuldades e das possibilidades dos alunos com deficiência. E que o município ainda carece muito de medidas que incentivem a participação mais efetiva da família no ambiente escolar e que criem redes de cooperação para auxiliar no desenvolvimento do aluno com deficiência. Seriam importantes medidas, como: palestras nas escolas para os pais dos alunos com deficiência sobre a importância da família trabalhando em conjunto com a escola para o 
aumento da qualidade de vida do aluno e seu desenvolvimento, incentivando a participação da família nas atividades escolares e no planejamento do currículo escolar, informando acerca da deficiência do aluno.

Com relação à atuação do município, vê-se que ainda é preciso que suas ações sejam mais organizadas, de forma a garantir o retorno esperado. Faz-se necessário que seja aprovado o Projeto Educação Inclusiva e que este cumpra todas as metas e objetivos. Na atualidade, somente a garantia de transporte aos alunos com deficiência é cumprida com eficiência, eficácia e efetividade, garantindo que o aluno tenha sua participação no AEE.

Por outro lado, é preciso capacitar os professores por meio de cursos de formação continuada, garantir uma remuneração adequada a estes profissionais, além de assegurar recursos financeiros e didático-pedagógicos suficientes para que a operacionalização dos trabalhos dos professores seja cumprida da melhor forma possível. Vale destacar que não é apenas a prática eficiente do gerenciamento educacional nas instituições e no município que irá garantir o sucesso da meta de construir um sistema educacional que acolha a todos os alunos em suas peculiaridades, mas uma verdadeira transformação dos paradigmas educacionais que estão impregnados no inconsciente das pessoas e que levem paulatinamente a uma modificação das condutas individuais e, finalmente, à transformação social.

\section{REFERÊNCIAS}

ARRUDA, Inácio. Direito da pessoa com deficiência: conhecer para exigir. Brasília: Senado Federal, 2010.

ARACOIABA, Projeto Educação Inclusiva. Aracoiaba. 2015.

(a), Escola de Ensino Fundamental Dra. Nágila Maria Pontes Paz Passos. Regimento Escolar. Aracoiaba, 2017

(b), Escola de Ensino Fundamental Dra. Nágila Maria Pontes Paz Passos. Projeto Político Pedagógico. Aracoiaba, 2017

BRASIL. Constituição (1988). Constituição da República Federativa do Brasil: promulgada em 5 de outubro de 1988. 48.ed. São Paulo: Saraiva, 2013

, Decreto 5.296, de 02 de dezembro de 2004. Regulamenta as Leis $n^{\text {os }} 10.048$, de 8 de novembro de 2000, e 10.098, de 19 de dezembro de 2000, e dá outras providências, 2004(a). Disponível em: $\quad<$ http://www.planalto.gov.br/ccivil_03/_ato20042006/2004/decreto/d5296.htm>. Acesso em: 06. Jul. 2017 
Decreto 6.571, de 17 de setembro de 2008. Dispõe sobre o atendimento educacional especializado. Secretaria de Educação Especial - MEC/SEESP, 2008. Disponível em: $<$ www.mec.gov.br/seesp>. Acesso em: 06. Jul. 2017.

, Decreto $\mathbf{n}^{0}$ 6.949, de 25 de agosto de 2009. Promulga a Convenção Internacional sobre os Direitos das Pessoas com Deficiência - ONU. DOU, Brasília, 2009.

, Decreto 7.611, de 17 de novembro de 2011. Dispõe sobre a educação especial, o atendimento educacional especializado e dá outras providências, 2011. Disponível em: $<$ http://www.planalto.gov.br/ccivil_03/_ato2011-2014/2011/decreto/d7611.htm>. Acesso em: 06. Jul. 2017

, Decreto Legislativo $\mathbf{n}^{0}$ 186, 24 de dezembro de 2008. Aprova o texto da Convenção sobre os Direitos das Pessoas com Deficiência e de seu Protocolo Facultativo, assinados em Nova Iorque, em 30 de março de 2007. Diário Oficial da União, Brasília, 2008

, Lei n. 9.394, de 20 de dezembro de 1996. Lei de Diretrizes e Bases da Educação Nacional. Disponível em: <www.planalto.gov.br/legislação>. Acesso em: 03. Jul. 2017

Lei complementar $n^{\circ}$ 101, de 04 de Maio de 2000. Estabelece normas de finanças públicas voltadas para a responsabilidade na gestão fiscal e dá outras providências, 2000. Disponível em: <http://www.planalto.gov.br/ccivil_03/leis/LCP/Lcp101.htm >. Acesso em: 06. Jul. 2017

, Ministério da Educação. Direito à Educação: Subsídios para a Gestão dos Sistemas Educacionais: Orientações Gerais e Marcos Legais. 2006. Disponível em: $<$ http://portal.mec.gov.br/seesp/arquivos/pdf/direitoaeducacao.pdf $>$. Acesso em: 10 jul. 2017

, Ministério da Educação Secretaria de Articulação Com os Sistemas de Ensino

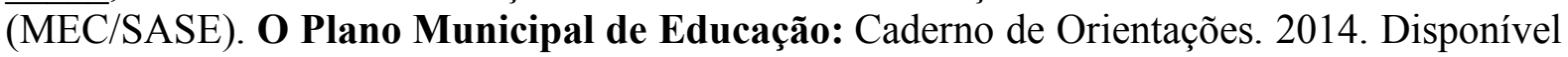
em: <http://pne.mec.gov.br/images/pdf/pne_pme_caderno_de_orientacoes.pdf $>$. Acesso em: 06 ago. 2017

(a), Ministério da Educação. Secretaria de Educação Especial. Marcos Político-Legais da Educação Especial na Perspectiva da Educação Inclusiva. 2010. Disponível em: $<$ http://portal.mec.gov.br/index.php?option $=$ com_docman\&view $=$ download\&alias $=6726$ marcos-politicos-legais\&Itemid=30192>. Acesso em: 15 jul. 2017

(b), Ministério da Educação. SEE. Manual de Orientação: Programa de Implantação de Sala de Recursos Multifuncionais, 2010. Disponível em: $<$ http://www.gestaoescolar.diaadia.pr.gov.br/arquivos/File/pdf/manual_salasrecursosmultifun cionais.pdf>. Acesso em: 12 jul. 2017

(c), Nota Técnica - SEESP/GAB No 11/2010, de 07 de maio de 2010. Orientações para a institucionalização da Oferta do Atendimento Educacional Especializado - AEE em 
Salas de Recursos Multifuncionais, implantadas nas escolas regulares. Diário Oficial União, Brasília, DF, 21 dez. 2007

\section{Orientações para implementação da política de educação especial na perspectiva da educação inclusiva. 2015.2 Disponível em: $<$ http://portal.mec.gov.br/index.php?option=com docman\&view=download\&alias=17237- secadi-documento-subsidiario-2015\&category_slug=marco-2015-pdf\&Itemid=30192>. Acesso em: 10 jul. 2017}

Política Nacional de Educação Especial na Perspectiva da Educação Inclusiva. Secretaria de Educação Especial - MEC/SEESP, 2008. Disponível em: $<$ www.mec.gov.br/seesp>. Acesso em: 03 maio 2017

, Portaria Normativa $\mathbf{N}^{\mathbf{0}} \mathbf{1 3}$, de 24 de Abril de 2007, Dispõe sobre a criação do Programa de Implantação de Salas de Recursos Multifuncionais. Disponível em: http://portal.mec.gov.br/index.php?option $=$ com_docman\&view $=$ download\&alias $=9935$ portaria-13-24-abril-2007\&Itemid=30192. Acesso em: 07 ago. 2017

(d), Resolução Nº . 4, de 13 de Julho de 2010. Institui as Diretrizes Operacionais para o Atendimento Educacional Especializado na Educação Básica. Disponível em: $<$ http://portal.mec.gov.br/dmdocuments/rceb004_10.pdf>. Acesso em: 07. ago. 2017

, Resolução No . 4, de 2 de outubro de 2009. Institui as Diretrizes Operacionais para o Atendimento Educacional Especializado na Educação Básica. Disponível em: $<$ http://portal.mec.gov.br/dmdocuments/rceb004_09.pdf>. Acesso em: 07. ago. 2017

, Ministério da Educação. Secretaria de Educação Especial. Educação Inclusiva: O Município. 2004(b). Disponível em: $<$ http://portal.mec.gov.br/seesp/arquivos/pdf/omunicipio.pdf $>$. Acesso em: 12 ago. 2017.

, Ministério da Educação Secretaria de Educação Especial. Educação Inclusiva: A Família. 2004(c). Disponível em: <http://portal.mec.gov.br/seesp/arquivos/pdf/afamilia.pdf >. Acesso em: 12 ago. 2017.

, Ministério da Educação Secretaria de Educação Especial. Educação Inclusiva: A Escola. 2004(d). Disponível em: <http://portal.mec.gov.br/seesp/arquivos/pdf/aescola.pdf $>$. Acesso em: 12 ago. 2017.

DELGADO, Adriana Patrício. O impacto das políticas públicas nas práticas escolares sob a ótica da avaliação de aprendizagem. Espaço do Currículo, Paraíba, v. 4, n. 2, p.162-171, 2012.

FÁVERO, Eugênia Augusta Gonzaga; PANTOJA, Luisa de Marillac P.; MONTOAN, Maria Teresa Eglér. Atendimento Educacional Especializado: Aspectos Legais e Orientações Pedagógicas. 2007.

GIL, Antonio Carlos. Como Elaborar Projetos de Pesquisa. 4. ed. São Paulo: Atlas, 2002. 
GODOY, Arilda Schmidt. Pesquisa qualitativa: tipos fundamentais. Revista de Administração de Empresas, São Paulo, v. 35, n. 3, p.20-29, mai./jun. 1995.

MOZZATO, Anelise Rebelato; GRZYBOVSKI, Denize. Análise de Conteúdo como Técnica de Análise de Dados Qualitativos no Campo da Administração: Potencial e Desafios. Revista de Administração Contemporânea, Curitiba, v. 15, n. 4, p.731-747, ago. 2011.

GOMES, Ana Valeska Amaral; BRITTO, Tatiana Feitosa de (Org.). Plano Nacional de Educação: Construção e Perspectivas. 2015.

ONU, Conferência Mundial Sobre Educação Especial. Declaração de Salamanca: Sobre Princípios, Políticas e Práticas na Área das Necessidades Educativas Especiais. 1994. Disponível em: < http://portal.mec.gov.br/seesp/arquivos/pdf/salamanca.pdf $>$. Acesso em: 15 jun. 2017.

PASSOS, Escola de Ensino Fundamental Dra. Nágila Maria Pontes Paz Passos. Regimento Escolar. Aracoiaba, 2017.

, Escola de Ensino Fundamental Dra. Nágila Maria Pontes Paz Passos. Projeto Político Pedagógico. Aracoiaba, 2017

PIANA, Maria Cristina. A construção do perfil do assistente social no cenário educacional. São Paulo: Editora UNESP, 2009.

SECCHI, Leonardo. Políticas Públicas: Conceitos, Esquemas de Análise, Casos Práticos. São Paulo: Cengage Learning, 2010. 134 p.

SOUZA, Dalva Inês de et al. Manual de orientações para projetos de pesquisa. Novo Hamburgo: $\quad$ Feslsvc, $2013 . \quad 55$ p. $\quad$ Disponível em: $<$ http://www.liberato.com.br/sites/default/files/manual_de_orientacoes_para_projetos_de_pes quisa.pdf $>$. Acesso em: 15 maio 2017 